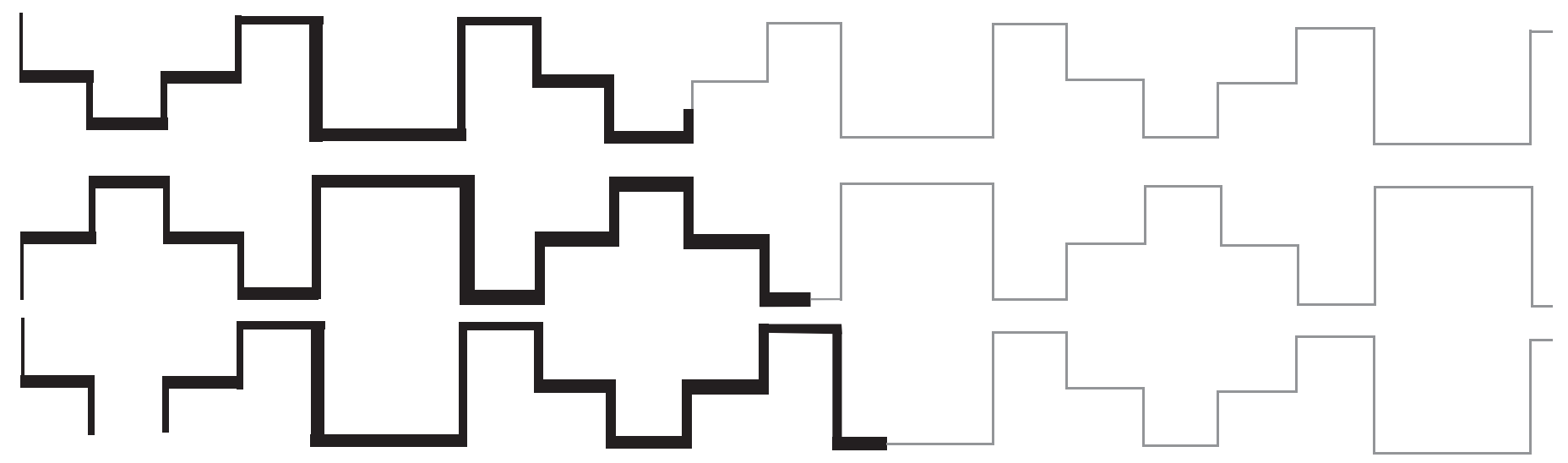

\title{
O lugar do outro: a imagem dos traçados urbanos como técnica de separação
}

\author{
Giovana Aparecida \\ Zimermann
}

\section{Resumo}

Este artigo investiga a crescente dificuldade de convívio na cidade contemporânea apoiado no cruzamento entre literatura e imagem. A urbe sofre uma vertiginosa transformação que expõe as diferenças econômicas, sociais, culturais, cada vez mais acentuadas, tornando o seu equacionamento um grande desafio. $\mathrm{Na}$ interpretação desse processo, destacam-se as manifestações das expressões artísticas, especialmente nos campos da literatura e do cinema. Buscando apoio nas possibilidades comparativas e na flexibilidade dos limites entre essas diferentes linguagens, o artigo procura estabelecer a hipótese da utilização da expressão artística como um dos mais importantes instrumentos que torna possível interpretar o espaço urbano e as relações entre este e seus habitantes. Trata-se, portanto, de investigar a transição da cidade contemporânea, que ameaça eclipsar-se diante da crescente intolerância.

Palavras-chave: cidade; cinema; literatura; conflitos urbanos.

\begin{abstract}
This article attempts to examine the growing difficulty of the urban communitarian experience under the light of a crossing between literature and image. The city currently undergoes a dizzying transformation which reveals economic, social, and cultural differences that look increasingly sharper, rendering their consideration a major challenge. Among interpretations of such process,
\end{abstract}


artistic readings stand out, especially within the fields of literature and film. Seeking support on the possibilities for comparison and on the flexibility of boundaries found in both these languages, this article tries to hypothesize artistic expression as one of the most important tools to interpret the urban space and its relations to its inhabitants, while trying to investigate the transition of the contemporary city, which threatens to disappear under the growing intolerance.

Key-words: city; film; literature; urban conflicts.

O perfil das cidades está sendo alterado pelas aglomerações humanas. Historicamente considerada o lugar da diversidade, a urbe vem se tornando menos tolerante. Em diversos meios de comunicação, podemos encontrar a manifestação clara de como a nossa sociedade vem construindo essa intolerância na cidade na constatação do medo urbano do outro. Essa leitura pode ser feita mediante um olhar atento ao próprio comportamento dos cidadãos, em que a perda da capacidade de abrigar as diferenças fica evidente, materializado na forma da organização dos espaços urbanos. Nessa medida, pelo desenho urbano, também é possível identificar um desenho antropológico e social, demarcando limites e estabelecendo a noção de pertencimento e não pertencimento, existência e coexistência. No caso do urbanismo, é a tomada de posse do ambiente natural e humano por todas as forças técnicas da economia capitalista que, ao desenvolver sua lógica de dominação absoluta, refaz a totalidade do espaço como seu próprio cenário, estratégias que Guy Deboard denominou como "técnica da separação". ${ }^{1}$ Os sintomas desse fenômeno, além de estampados nos jornais e na própria publicidade, têm se apresentado, também, de forma cada vez mais frequente em um dos meios mais sensíveis a detectar e interpretar as transformações na vida humana: $a$ arte.

As evidências da divisão social já apareciam nos registros literários e pictóri$\cos$ da Modernidade. Entre outros autores, Baudelaire e Alan Poe apresentaram as transformações da Paris das reformas urbanas de Eugene Haussmann e a Londres da Revolução Industrial. A realidade miserável de grande parte dos trabalhadores foi também registrada em gravuras de Gustav e Doré. Já o cinema criado no auge da metrópole moderna, necessitava tanto do aparato industrial quanto do adensamento das cidades, por ser uma arte de reprodução e de massa. Desde seu surgimento, fins do século XIX, era uma forma de entretenimento essencialmente urbana e deve muito de sua natureza ao desenvolvimento da cidade. Benjamin observou que a reprodutibilidade técnica da obra de arte alterava a relação das massas com a arte. "Reacionárias, diante, por exemplo, de um Picasso, transformam-se nas mais progressistas frente a um Chaplin". ${ }^{2} \mathrm{O}$ autor referia-se ao comportamento do observador que experimentava uma ligação íntima e imediata com a vivência e o prazer do espetáculo cinematográfico.

A maneira como as cidades são retratadas nos filmes lhes dá significados que podem contribuir, intencionalmente ou não, para a difusão de um conjunto de crenças

1 No caso do urbanismo o que está em jogo é o equipamento da base geral dessas forças, do tratamento do solo que convém a seu desenvolvimento, à própria técnica da separação. DEBORD, Guy. A sociedade do espetáculo: Comentários sobre a sociedade do espetáculo. Rio de Janeiro: Contraponto Editora Ltda, 1992, p. 112.

2 BENJAMIN, Walter. A Obra de Arte na Era de sua Reprodutibilidade Técnica. In:___. Magia e técnica, arte e política: ensaios sobre a literatura e história da cultura. 5. ed. São Paulo: Brasiliense, 1993, p. 100. 
e valores muitas vezes ligados às estruturas: cultural, política e econômica. O questionamento e a possível desagregação dos valores que se haviam originado da modernidade e foram tematizados pelos movimentos artísticos da vanguarda, ainda não tinham alcançado o cinema, que criava a ilusão de estar restituindo o real, no entanto ele reservava um potencial de crítica social que foi vislumbrado por Benjamin. "Não contestamos que o filme atual, em casos particulares, possa promover, além disso, uma crítica revolucionária das relações sociais, ou mesmo das de propriedade."’

A cidade, desde seus primórdios, possui a inexorável ligação entre o seu espaço físico, as relações entre seus habitantes e a forma de manutenção e controle dessas relações. É preciso, portanto, tratar os discursos e representações sobre a cidade como construções simbólicas que estão plenas de valores sociais. Sabemos que o acontecimento do fenômeno urbano só será possível mediante ajustes entre aqueles que participam da vida de uma cidade. Quanto mais avançamos no tempo, mais a aceleração dos processos sociais e as modificações dos espaços urbanos tornam-se vertiginosas, mais complexas, portanto, torna-se necessário seu acompanhamento e o estabelecimento de normas de convivência. Nas últimas décadas, os estudos que associam "cultura" e "meio urbano" ganharam novamente centralidade. São diversas obras que tocam em um ponto crucial para o estudo da cidade contemporânea, vindas da literatura, das artes plásticas e do cinema. Tratam dos perigos existenciais, em especial das dificuldades de conviver com o outro, de conseguir dividir o mesmo espaço, tendo em vista os interesses divergentes e conflitantes.

$\mathrm{Na}$ contemporaneidade, algumas obras tentam interpretar não apenas as modificações causadas pela urbanização crescente, mas as transformações que acontecem nas relações entre os agentes da dinâmica urbana, ou seja, a diminuição da solidariedade e, por consequência, o crescimento da intolerância. A 27. ${ }^{a}$ Bienal de São Paulo discutiu a condição (viver-juntos), utilizando um termo de Roland Barthes que foi a inspiração para o título: "Como viver juntos". Entre inúmeras propostas artísticas, Mechac $\mathrm{Gaba}^{4}$ apresentou Sweetness (doçura), uma maquete de uma cidade feita de açúcar. Em seu discurso, o artista fala que o tema "Como viver juntos" expõe muitas interrogações, e complementa,

Para que as pessoas possam viver juntas, é preciso harmonia, doçura e amor. Seria necessário a anistia, e anistia é o perdão. [...] é necessário, porém, que ela seja cultivada para que os homens possam curar suas dores neste mundo de tolerâncias ilusionistas. Não se poderia consumir o açúcar nem o diamante, quando estes são vistos na perspectiva da história de sua extração. ${ }^{5}$

Virginia de Medeiros, artista brasileira, fala da dimensão de troca. Essa artista teve o seu trabalho intitulado Studio Butterfly. Seu trabalho desenvolveu-se no universo das travestis na cidade baixa, em Salvador. "Só existe troca se existir a instância do afeto.

3 Idem, ibidem. p. 96.

4 LAGNADO, Lisette; PEDROSA, Adriano. (Curadores). Como viver junto. São Paulo: Fundação Bienal, 2006. Catálogo da $27^{\mathrm{a}}$ Bienal Internacional de São Paulo, 2006.

5 Idem, ibidem. 
A troca é o afeto, e sem afeto nunca poderia ter feito essa obra”.

\begin{abstract}
Aluguei uma sala num edifício comercial, no centro de Salvador, localizado numa área onde vivem e trabalham as travestis. Montei ali um estúdio para recebê-las, ornamentei uma poltrona à qual dei o nome de "poltrona de afetos". Nelas as travestis contavam suas histórias. Posicionei-me como mediadora de uma fala que se encontra aprisionada por uma imagem estereotipada. Tive como desafio expressar a vida dessas travestis que atravessaram a minha vida, me fazendo experimentar um estado de vibração nunca antes sentido - me tornei travesti; com toda a diferença que me cabe. ${ }^{6}$
\end{abstract}

Um congresso que tratou da confiança e do medo de quem vive nas cidades teve como principal objetivo avaliar os problemas de convivência. O conferencista Bau$\operatorname{man}^{7}$ declarou que viver numa cidade significa viver junto com estrangeiros, que jamais deixaremos de ser estrangeiros, e não interessados em interagir. A partir do momento em que, no mesmo espaço físico - a cidade - as pessoas são amontoadas e obrigadas a conviver próximas, diversas "distâncias" aparecem - culturais, sociais, religiosas - as pactuações para o convívio urbano precisam ser refeitas, mas ao que assistimos é a construção de fronteira: física, econômica e social. Bauman evidencia que nas cidades é possível observar o que chama de "furiosa atividade de traçar fronteira entre as pessoas", e quanto mais o espaço e a distância se reduzem, maior é a valorização dos limites sociais estabelecidos pelos seus habitantes, "quanto mais é depreciado o espaço, menos protetora é a distância, e mais obsessivamente as pessoas traçam e deslocam fronteiras". ${ }^{8}$ A "Arquitetura do medo isola cidadão e provoca fobia" social, foi a manchete da Folba de São Paulo, assinada por Antonio Arruda em primeiro de maio de 2003.

Muralhas, seteiras, fossos, arames farpados, lanças. Não se fala aqui de um castelo medieval, mas de edifícios e casas de bairros de classe média e alta de São Paulo e do Rio de Janeiro que cada vez mais incorporam à sua arquitetura elementos utilizados na Idade Média. Há ainda as residências que se assemelham mais a presídios de segurança máxima, com sistemas sofisticados de alarmes, sensores e câmeras de vídeo. ${ }^{?}$

O perigo do isolamento doméstico, ou dentro dos condomínios fechados, é de impedir que as pessoas, principalmente os jovens, desenvolvam uma convivência urbana plena e uma aceitação do outro, gerando atritos cada vez mais constantes nas grandes cidades. Em alguns casos, verdadeiros atos de barbárie. "No Rio - jovens, filhos da classe média alta, universitários, moradores de condomínio de luxo e capazes de um ato de barbárie e violência". ${ }^{10} \mathrm{O}$ noticiário documentou que no dia 23 de junho de 2007 cinco jovens, ou seja, delinquentes, roubaram e agrediram a socos e pontapés uma moça

\footnotetext{
6 Idem, ibidem, p. 242

7 BAUMAN, Zygmunt. Confiança e medo na cidade. Rio de Janeiro: Jorge Zahar Ed., 2009.

8 Idem, ibidem.

9 ARRUDA, Antonio. Arquitetura do medo. Folha de São Paulo. Disponível em: <www1.folha.uol.com.br/folha/equilíbrio/notícias/ult263u2335.shtml > . Acesso em: 20 abr. 2010.

10 Disponível em: <www.direitos.org.br/index. > Acesso em: 22 abr. 2010.
} 
(empregada doméstica) que estava em um ponto de ônibus na Barra da Tijuca, bairro de elite na zona oeste do Rio. Um dos três agressores justificou o crime à polícia dizendo que acharam que se tratava de "uma vagabunda".

Em Cidades estreitamente vigiadas, Pechman fala dos comportamentos que "vão se moldando e se inserindo em uma sociabilidade que vai se legitimando a ponto de se tornar um ethos a partir do qual se forjam as representações do que devam ser a ordem". ${ }^{11}$ Elucida que o estabelecimento dos primeiros pactos de convivência surgiu com os gregos com a politike (política), ou seja, a habilidade no trato das relações humanas. Esse termo, não por acaso, deriva linguisticamente de pólis (cidade), que também origina politeia (polícia), a administração encarregada de manter as disposições que servem de garantia à ordem pública. A cidade apresenta, portanto, desde seus primórdios, linguística e socialmente, essa ligação entre o espaço físico, as relações entre os habitantes e a forma de manutenção e controle dessas relações. Pechman fala, também, da espera pelo bárbaro, ou seja, da utilidade do bárbaro para a cidade.

[...] a figura do bárbaro é recorrente nas representações formuladas sobre a sociedade moderna em formação. Funcionando como um espelho no qual a sociedade dita civilizada se mira, a barbárie é percebida como tudo aquilo que está fora do mundo civilizado, mas que reflete inevitavelmente as imagens da própria civilidade. A civilização, portanto não dispensa a barbárie; faz-lhe o parto, dá-lhe de comer, e... deserda-a. ${ }^{12}$

De acordo com Wille Bolle, a caducidade das grandes cidades vem se acentuando do Modernismo em diante. Para o autor "às esperanças de emancipação política e social, tais como foram despertadas e fomentadas pelo Modernismo, se sobrepôs na crítica e no ensaísmo dos anos 1970 e 1980 um ceticismo crescente". ${ }^{13}$ Torna-se, portanto, esse Modernismo um movimento de origem essencialmente urbana, cujo "habitat natural" seria a cidade democrática. E sabemos que as sociedades democráticas são menos propensas a pautarem-se por regras estabelecidas, já que a sua constituição pressupõe a igualdade entre cidadãos de todas as classes. Somado esse raciocínio ao fato de que essa igualdade prometida não se verifica na prática, podemos começar a vislumbrar as origens da frustração carregada por uma grande parcela da população urbana. $\mathrm{Ou}$ seja, o Modernismo, construído sobre a base de uma promessa abstrata de igualdade, que se revela posteriormente fictícia, conduz a um progressivo desapontamento. Isso, segundo Bolle, aparece na literatura brasileira urbana dos nossos dias - "ficcionistas como Loyola Brandão, João Antônio, Ivan Angelo, Ruben Fonseca e outros - mostram, como temas preponderantes, a pobreza, a miséria, a violência, a degradação humana a ausência de esperança". ${ }^{14}$

Escrito por Paulo Lins e publicado em 1997, Cidade de Deus ${ }^{15}$ é um dos romances brasileiros mais importantes da década de 90 . O livro acompanha as transfor-

11 PECHMAN, Robert. Cidades estreitamente vigiadas: o detetive e o urbanista. Rio de Janeiro: Casa da Palavra, 2002. p. 77.

12 Idem, ibidem. p. 23

13 BOLLE, Wille. Fisiognomia da Metrópole Moderna: Representações da História em Walter Benjamin. São Paulo: Editora da Universidade de São Paulo, 1994. p.35.

14 Idem, ibidem.

15 LINS, Paulo. Cidade de Deus. São Paulo: Cia. das Letras, 2007. 
mações sociais pelas quais passou o bairro carioca de Cidade de Deus - modelo para o que aconteceu em todo o País. Quando, nos anos 1990, o tráfico de drogas substituiu a pequena criminalidade da década de 60 , a violência impõe-se e a guerra começa. Cinco anos depois da publicação do romance, chega aos cinemas o filme Cidade de Deus, para contar, com a agilidade cinematográfica, como o crime organizado instalou-se nas favelas do Rio de Janeiro. O filme evidencia a coexistência da favela em relação à cidade: a degradação humana, a falta de esperança dos moradores que, mesmo não participando da criminalidade, pagam o preço por morar na favela, carregando o estigma de abrigo da violência, causadora do medo e, por consequência, justificando a segregação aos moradores. O filme é narrado por um jovem, o Buscapé, que viveu paralelamente as alterações do bairro. Por ser morador da favela e conhecer os líderes do tráfico, consegue fotografá-los exibindo suas armas, o que lhe garante uma oportunidade de ser fotógrafo. Finalmente fotografa também a corrupção da polícia em uma transação de suborno com os traficantes.

Em Tropa de Elite, o tráfico e a corrupção de parte da polícia também são apresentados como estrutura viciosa de manutenção da criminalidade. Com direção de José Padilha, o filme também retrata a realidade de uma favela do Rio de Janeiro, dominada pelo tráfico e resultando em uma trincheira de guerra civil. Rodrigo Pimentel, um dos roteiristas ${ }^{16}$ do filme, é capitão reformado da Polícia Militar do Rio de Janeiro e exintegrante do Batalhão de Operações Especiais (Bope).

Para os policiais do Bope, na perspectiva apresentada pelo filme, o inimigo não tem apenas uma cara - a dos "bandidos". O filme despertou uma importante discussão ao colocar os usuários de drogas como um dos maiores responsáveis pela violência urbana, uma vez que financiam o comércio ilegal de entorpecentes. Os métodos usados por essa "tropa de elite" é baseado em: tortura física e psicológica, o que provocou críticas exaltadas à mensagem que o filme transmitiria - na imprensa internacional chegou a ser classificado de fascista por alguns críticos. A pedido da revista Veja, o instituto Vox Populi realizou uma pesquisa para medir o impacto do filme Tropa de Elite entre os espectadores. Na opinião de $72 \%$ dos entrevistados, os criminosos que aparecem no filme são tratados como merecem. Quase $80 \%$ deles concordam que a polícia é apresentada com fidelidade - ou seja, elementos honestos e elementos desonestos. Tropa de Elite agrada também por abordar literalmente a responsabilidade dos usuários de drogas pela geração de violência. O Capitão Nascimento diz que o playboy que fuma um cigarro de maconha é o responsável pela morte de um traficante abatido pelo Bope. A afirmação encontra eco entre a população. ${ }^{17}$

O debate público sobre a violência e a criminalidade, especialmente com a frágil democracia brasileira, é muito perigoso, alerta a antropóloga Alba Zaluar. Em virtude do medo e da indignação perante a criminalidade dos dias de hoje, a população não está considerando a própria liberdade e acredita que a ordem deve ser mantida a qualquer preço.

[‥] de um lado estão os libertários que, a partir da afirmação de que a sociedade é que é criminosa - na medida em que, por

16 Roteiristas de Tropa de Elite: Rodrigo Pimentel, Bráulio Mantovani e José Padilha.

17 Revista Veja - Edição 2030, 17 de outubro de 2007. 
ser desigual e iníqua, sustenta uma ordem que contém, controla e limita desejos e paixões individuais -, acabam por atacar qualquer ordem social, especialmente quando parte do Estado. Viva a desordem, eis o seu lema. No outro extremo estão os que em virtude do medo e da indignação ante os horrores praticados pelos insubordinados bandidos de hoje, pensam que a ordem deve ser mantida a qualquer preço, sem considerar as perdas da liberdade individual. Viva a ordem, entregue-se tudo a Leviatã: eis o seu atual desejo. A manutenção do atual dilema pode nos levar ou ao caos e à extensão do estado de guerra a todos, ou então ao recrudescimento da ordem autoritária. ${ }^{18}$

As diferenças, em vez de transformarem-se em riquezas - do ponto de vista cultural e social - são instrumentos de separação. A cidade transforma-se em espaço de exclusão. A distância em relação ao outro aumenta e fica evidente pela presença dos muros.

$\mathrm{Na}$ Europa, o filme Entre les murs expõe as diferenças sociais na França contemporânea. A escola é o lugar de mistura étnica e social, tratada no filme como um microcosmo, uma zona de conflito, e as diferentes culturas são evidenciadas como refúgio para defesa dos jovens que não têm a noção de pertencimento.

Para aproximarmo-nos da raiz desses conflitos, é necessário retroceder à formação da nacionalidade francesa, ou seja, às ideias iluministas oriundas da Revolução Francesa de 1789 que pregavam "igualdade, liberdade e fraternidade". O Iluminismo gerou uma convicção de que a França era um modelo de civilização a ser seguido, resultando em um discurso de dominação cultural e, de certa forma, atribuindo a inferioridade às outras culturas. No século XIX, quando as potências europeias dividiram o continente africano, os países colonizadores impuseram critérios étnicos, missionários, ou seja, características civilizatórias, aos países dominados.

Os critérios étnicos introduzidos criaram distinção entre dominadores (brancos) e dominados (outra cor). Para tanto, uma série de pretextos foram invocados: superioridade da raça branca, incapacidade de os "nativos" dirigirem ou explorarem por conta própria seus recursos naturais, e até mesmo a grande missão de levar aos povos de cor ignorantes as vantagens da cultura intelectual, social, científica, industrial e artística das raças brancas superiores. ${ }^{19}$

Entre les murs $^{20}$ é uma adaptação do livro homônimo de François Bégaudeau, um professor de francês que lecionou por alguns anos na periferia de Paris. O texto de Bégaudeau assemelha-se a um diário, no qual ele vai anotando sua experiência com os alunos de uma turma do ensino médio na periferia de Paris. De certa forma, o livro já reserva um aspecto de roteiro cinematográfico, no qual os diálogos são mantidos e o detalhamento da linguagem confere uma imagética que se traduz de grande utilidade

\footnotetext{
18 ZALUAR, A. Crime e castigo vistos por uma antropóloga. In: (Org.). Integração perversa: pobreza e tráfico de drogas. Rio de Janeiro: Editora FGV, 2004. p. 23

19 BICALHO, 1994, p.12

20 O filme foi dirigido por Laurent Cantete, recebeu Palma de Ouro no Festival de Cannes em 2008 e foi indicado na categoria de Oscar de melhor filme estrangeiro, no mesmo ano.
} 
para a produção audiovisual. O aspecto marcante e relevante da obra é, sem dúvida, a diferença cultural e social que gera incompreensão e atrito entre ambas as partes do muro a que se refere o título: de um lado está François Marin, um professor de francês vivido por François Bégaudeau, de outro, está um grupo de alunos entre 13 e 15 anos, composto por negros africanos, asiáticos, latino-americanos e franceses. O filme está no limiar da ficção e do documentário. Os debates são tão vigorosos que, em alguns momentos, lembram um reality show, uma vez que o professor e os alunos representam seus próprios papéis, incluindo seus nomes, que são preservados. Entre os alunos estão Khoumba, Mohammed, Souleymane, Mezut, Bien-Aimé, Djibril, Frida, Ming, Sandra, entre outros. Por um lado, parece que os jovens podem criar seus próprios diálogos dando a sensação de que aproveitam o espaço para falar da realidade, utilizando a linguagem como campo de batalha, por outro, o filme evidencia os jovens não como franceses, mas como o imigrante de outra etnia que se esforça ou não para assimilar a cultura francesa. As dificuldades e os conflitos entre as duas partes aparecem praticamente ao longo de todo o filme. É possível perceber a pressão que os adolescentes enfrentam, sendo marginalizados e excluídos da sociedade: não se reconhecem franceses, enfrentam dificuldades para conseguir o primeiro emprego, poucos demonstram estímulo para estudar e garantir uma vida melhor. As diferenças étnicas também são evidenciadas constantemente. Nesse sentido, as diferenças, em vez de transformarem-se em riquezas - do ponto de vista cultural e social - são instrumentos de separação.

O filme tenta dar uma finalização com os alunos e o professor falando e jogando futebol. Os meninos manifestam suas opiniões e questionam o professor quando ele também alega que não irá torcer pela França. "Mas o Sr., prô? Nem o Sr. vai torcer pela França?" Djibril, quando descreve suas características ao declarar-se Malinês: "Sou Malinês, me orgulho disso, pois este ano o Mali vai participar da Copa da África. Eles caíram com a Líbia, Argélia e Moçambique". ${ }^{21}$ Os jovens torcem pelos times de futebol dos países de origem de suas famílias, em uma tentativa de imaginar uma nação à qual possam pertencer. Para Hall, uma nação é uma comunidade simbólica, não é apenas uma entidade política, mas um sistema de representação cultural, "a identidade nacional é uma comunidade imaginada". ${ }^{22} \mathrm{O}$ que aconteceu com a França parece ter sido uma assimilação cultural ${ }^{23}$ mal-sucedida, e o filme Entre lês murs evidencia essa realidade, porém não fala somente do muro entre os alunos e os educadores, ou mesmo da cidade representada pela escola, fala também do muro intransponível que separa os jovens da noção de pertencimento, fator de manutenção dos conflitos.

As obras aqui abordadas, sobretudo os filmes, apresentam realidades contemporâneas em continentes distintos e com distintas características antropológicas e sociais, porém o que fica evidente é a falta do sentido de pertencimento. No momento em que a sociedade perde a capacidade de construir a identidade de seus cidadãos mediante a cidadania, ou seja, pelo sentimento de pertencer a um conjunto, perde também a liderança. Partindo desse raciocínio, a cidade pode ser considerada o lugar onde tudo

21 Idem, ibidem, p. 17, 18.

22 ANDERSON apud HALL, 2006, p. 51.

23 O conceito de assimilação cultural é utilizado para entender a denominação cultural francesa sobre as diferentes etnias africanas durante o imperialismo, por meio de um mecanismo de imposição da cultura francesa e negação cultural dos povos dominados. 
pode acontecer. E é exatamente essa divisão, sobretudo entre as classes, que torna a imprevisibilidade da cidade um fator de risco às relações humanas. Se já não há mais unidade entre os habitantes de um mesmo espaço sob o conceito de cidadãos, deixa de existir a possibilidade das reações, as quais passam pelas vias da polidez, da solidariedade, da amizade, da gentileza, que torna possível o convívio na urbe. Assim, quando o outro é o desconhecido, que se mostra apenas em uma via midiática estereotipada, mediante rótulos: drogados, travestis, prostitutas, mendigos, favelados etc., já não se vê mais o indivíduo como semelhante, perde-se a motivação para reagir a ele com afeto. A estruturação das relações passa a ser mantida por uma frieza e distanciamento, privilegiando as relações entre classes homogêneas e não mais à vida urbana como um todo, ou seja, está decretada a caducidade da esfera pública.

\section{Referências bibliográficas}

ARENDT, Hannah. Sobre a violência. Rio de Janeiro: Ed. Relume Dumará, 1994.

BAUMAN, Zygmunt. Confiança e medo na cidade. Rio de Janeiro: Jorge Zahar Ed., 2009.

BÉGADEAU, François. Entre os muros da escola. São Paulo: Martins, 2009.

BENJAMIM, Walter. Passagens. Belo Horizonte: Editora UFMG, 2006.

. A Obra de Arte na Era de sua Reprodutibilidade Técnica. In:

. Magia e técnica, arte e política: ensaios sobre a literatura e história da cultura.

5. ed. São Paulo: Brasiliense, 1993.

BOLLE, Wille. A Fisiognomia da metrópole moderna: representações da história em Walter Benjamin. São Paulo: Editora da Universidade de São Paulo, 1994.

DEBOARD, Guy. A Sociedade do Espetáculo: comentários sobre a sociedade do espetáculo. Rio de Janeiro: Contraponto Editora Ltda. 1992.

LINS, Paulo. Cidade de Deus. São Paulo: Companhia das Letras, 2007.

PECHMAN, Robert M. Cidades estreitamente vigiadas: o detetive e o urbanista. Rio de Janeiro: Casa da Palavra, 2002.

LAGNADO, Lisette; PEDROSA, Adriano. (Curadores). Como viver junto. São Paulo: Fundação Bienal, 2006. Catálogo da 27ª Bienal Internacional de São Paulo, 2006.

ZALUAR, A. Crime e castigo vistos por uma antropóloga. In: (Org.). Integração perversa: pobreza e tráfico de drogas. Rio de Janeiro: Editora FGV, 2004. 